\begin{abstract}
OBJECTIVES: In this study, we aimed to investigate plasma homocysteine (Hcy) and serum C-reactive protein (CRP) levels in hemodialysis (HD) and continuous ambulatory peritoneal dialysis (CAPD) patients, and the relation among them.

Materials and methods: This study was carried out on 52 HD patients, 26 CAPD patients and a control group of 22 healthy persons. Blood samples were taken from the patients for Hcy and CRP measurements.

Results: Serum CRP level was found to be high in $48.1 \%$ of HD patients, $69.2 \%$ of CAPD patients and $4.5 \%$ of the healthy control group. Plasma Hcy level was found out to be above the normal limits in $73.1 \%$ of HD patients, $65.4 \%$ of CAPD patients and $9 \%$ of the healthy control group. There was a significant positive relation $(r=0.384, p<0.001)$ between the levels of plasma Hcy and serum CRP in HD and CAPD patients.

Conclusion: The high levels of Hcy and CRP were found out to be higher in HD and CAPD patients than in the control group. In order to determine the risk rate of HCy and CRP for coronary artery disease, extensive investigations are required in patients with chronic renal failure that also have coronary artery disease.
\end{abstract}

Key words: Homocysteine, C-reactive protein, Hemodialysis, Continuous ambulatory peritoneal dialysis

\section{The effects of hemodialysis and peritoneal dialysis on serum homocysteine and C-reactive protein levels}

\author{
Ali Borazan ${ }^{1, C A}$, Selim Aydemir ${ }^{1}$, Mehmet Sert ${ }^{1}$ and \\ Ahmet Yilmaz ${ }^{2}$
}

'Zonguldak Karaelmas University Faculty of Medicine Internal Medicine, İc Hastalıkları ABD 67600 Zonguldak, Turkey ${ }^{2}$ Kocaeli University Faculty of Medicine Internal Medicine, Kocaeli, Turkey

\author{
${ }^{\mathrm{CA}}$ Corresponding Author \\ Tel: +3722610169 \\ Fax: +3722610155 \\ E-mail: aliborazan@mail.com
}

\section{Introduction}

Cardiovascular diseases are the major reason for mortality and morbidity of patients with chronic renal failure. ${ }^{1}$ The cardiovascular death rate in hemodialysis (HD) patients is predicted as 9\% per year and those in patients with chronic renal failure are 10-fold to 20 -fold higher than in the normal population. ${ }^{1,2}$

It is noteworthy that the risk factors defined for coronary artery disease such as heredity, hypertension, diabetes, smoking, and a high level of blood lipids had been shown even at the earliest stages of renal failure. ${ }^{2,3}$ In recent times the finding of high serum C-reactive protein (CRP), which is the marker of both hyperhomocysteinemia and inflammation, is considered a high risk factor for atherosclerotic vascular diseases in patients with chronic renal diseases, but some studies found no association or only a small association between plasma homocysteine (Hcy) levels and cardiovascular disease..$^{2,4,5}$

In this study, we aimed to examine the serum levels of plasma Hcy and serum CRP and the relationship between CRP, Hcy, and measures of therapy adequacy (Kt/V, serum albumin) in patients with chronic renal failure, in HD patients and in treated continuous ambulatory peritoneal dialysis (CAPD) patients.

\section{Patients and method}

This study was carried on 52 patients (19 female, 33 male) undergoing HD due to the end stage of renal failure, 26 patients (nine female, 17 male) undergoing CAPD and 22 healthy persons (eight female, 14 male) as a control group in our center after gaining their written approval.

Seven HD patients and four CAPD patients of 11 patients had previously diagnosed coronary artery disease (five of them had a coronary by-pass operation and six of them were having medical treatment).

Blood samples for urea, creatinine, total cholesterol, high-density lipoprotein (HDL)-cholesterol, low-density lipoprotein (LDL)-cholesterol, triglyceride, total protein, albumin, CRP, and Hcy levels were taken from the subjects in the morning after $12 \mathrm{~h}$ of fasting. The subjects were also evaluated for body mass index (BMI), dialysis time, dialysate volume and adequacy of dialysis $(\mathrm{Kt} / \mathrm{V})$. In addition to these, the difference between the groups and the relationship between CRP and Hcy levels and the other parameters were assessed.

Ambulatory HD patients were hemodialyzed on hollow-fiber polysulfone membrane dialysators with a $1.2 \mathrm{~m}^{2}$ surface area (Hemoflow $\mathrm{F} 5$ and Polysulfon UF 4.0; Fresenius, Germany) with bicar- 
bonate containing solutions two or three times weekly for $4 \mathrm{~h}$.

Peritoneal dialysis solutions of 2-2.5 1 with $1.36 \%$, and when necessary $3.86 \%$, glucose were used three or four times a day by the patients using CAPD. All patients ate a chronic renal failure diet and the control group was fed the normal diet.

The serum urea $(10-50 \mathrm{mg} / \mathrm{dl})$, creatinine $(0.8-1.2 \mathrm{mg} / \mathrm{dl})$, total cholesterol $(0-200 \mathrm{mg} / \mathrm{dl})$, HDL-cholesterol (40-80 mg/dl), LDL-cholesterol (50-160 mg/dl), triglyceride $(0-200 \mathrm{mg} / \mathrm{dl})$, total protein $(6.4-8.3 \mathrm{~g} / \mathrm{dl})$ and albumin $(3.5-5 \mathrm{~g} / \mathrm{dl})$ levels were studied at the central laboratory. The serum CRP level was measured on a Behring BN100 (Behring, Marburg, Germany) that uses the nepholometric method; plasma homocysteine was assessed by the fluorescense polarization immunoassay (Abbott IMX Instruments, Chicago, IL, USA) method. Three samples for serum CRP and Hcy levels were obtained from each patient over a 1 -week to 2 -week period. The values of CRP were considered normal when $<0.8 \mathrm{mg} / \mathrm{dl}$, and the value of Hcy was considered normal when $<15 \mu \mathrm{mol} / 1$.

For BMI, the formula of body weight $(\mathrm{kg}) /$ height $\left(\mathrm{m}^{2}\right)$ was used.

The adequacy of dialysis (Kt/V) was calculated with the $\mathrm{Kt} / \mathrm{V} \quad($ Jindal $)=(0.04 \times \mathrm{PRU})-1.2$ and $\mathrm{Kt} / \mathrm{V}$ (Daurgidas) $=\ln (\mathrm{R}-0.03-0.75 \cdot \mathrm{UF} / \mathrm{W})$ formulas.

The Kt value in CAPD is the 24-h dialysate output (DV): $\quad \mathrm{DV}=0.23 \times \mathrm{IBW}-(2.7+1.44 \times \mathrm{Cr}), \quad$ where IBW is the ideal body weight and $\mathrm{Cr}$ is the residual renal clearance (1/day).

The possibility of infection was investigated in subjects whose CRP levels were high, by determining the erythrocyte sedimentation rate and the presence or absence of leucocytosis. Blood samples for CRP were retaken from patients with an infection 21 days after appropriate treatment.

\section{Statistical analysis}

Results are expressed as mean \pm standard deviation. Statistical comparisons were evaluated by computer using the Statistical Package for Social Science for Windows, version 9.0, system (Release 9.0.0 Standard version, Copyright SPSS Inc., 1989-1999). Values between groups were compared using one-sided analysis of variance, and significant differences were analyzed using Student's $t$-test. The relationship between serum CRP and Hcy levels and the other factors, was determined by Pearson's correlation test. $p<0.05$ was considered statistically significant.

\section{Results}

Of the $52 \mathrm{HD}$ subjects included in this study, eight were applied HD twice a week and 44 subjects were applied HD for $4 \mathrm{~h}$ three times a week. The mean age of the subjects was $46.6 \pm 14.8$ years (age range, $22-$ 64 years) and the mean HD time was $29.5 \pm 11$ months (range, 9-48 months). Four of the 24 CAPD subjects had three exchanges and 22 of them had four exchanges of $2-2.5 \mathrm{l} / \mathrm{day}$, and the mean age among them was $44.6 \pm 13.5$ years (age range, $20-57$ years) and the mean CAPD time was $18.3 \pm 10$ months (range, 8-42 months). The mean age in the healthy control group was $45.5 \pm 15.8$ years (age range, 24-62 years). The etiologies of the chronic renal disease in the studied subjects are presented in Table 1 . The age, gender, BMI, dialysis period, total serum cholesterol, HDL-cholesterol, LDL-cholesterol, triglyceride, total protein, albumin, C-reactive protein, Hcy, dialysate output and mean Kt/V values and the results of the statistical analysis are presented in Table 2 .

The mean serum CRP level was found to be $8 \pm 4.5 \mathrm{mg} / \mathrm{dl}$ in the HD patients, $12.8 \pm 9.7 \mathrm{mg} / \mathrm{dl}$ in the CAPD patients and $0.3 \pm 0.5 \mathrm{mg} / \mathrm{dl}$ in the control group. High serum CRP levels were found in 25 of the HD subjects (48.1\%), 16 of the CAPD subjects (77.7\%) and in one member of the healthy control group (4.5\%). In the HD and CAPD subjects, no significant relationship could be found between the CRP levels and the age, gender, BMI, dialysis time, total cholesterol, HDL-cholesterol, LDL-cholesterol and total protein values $(p>0.05)$. In the HD subjects a negative relationship was present between the serum CRP level and the Kt/V ratios $(r=-0.436$, $p<0.05)$, and albumin levels $(r=-0.325$, $p<0.001)$. In the CAPD patients there was a negative relationship between the serum CRP levels and the dialysate volume $(r=-0.265, p<0.001)$, and the albumin values $(r=-0.462, p<0.05)$.

The mean serum Hcy level was found to be $32.5 \pm 14.3 \mu \mathrm{mol} / 1$ in HD patients, $30.4 \pm 18.7 \mu \mathrm{mol} / 1$ in CAPD patients and $13.24 \pm 5.26 \mu \mathrm{mol} / \mathrm{l}$ in the control group. The serum total Hcy level was above the normal limits in 38 of HD cases (73.1\%), 17 of

Table 1. The primary diseases of the patients

\begin{tabular}{lcc}
\hline Primary disease & Hemodialysis & $\begin{array}{c}\text { Peritoneal } \\
\text { dialysis }\end{array}$ \\
\hline Diabetic nephropathy & 12 & 7 \\
Chronic glomerulonephritis & 10 & 4 \\
Hypertensive nephropathy & 5 & 3 \\
Chronic pyelonephritis & 4 & 2 \\
Obstructive nephropathy & 4 & 2 \\
Polycystic renal disease & 6 & - \\
Amyloidosis & 2 & 2 \\
Etiology is not known & 9 & 6 \\
Total & 52 & 26 \\
\hline
\end{tabular}


Table 2. Mean values of clinical and biochemical values of the groups

\begin{tabular}{|c|c|c|c|c|}
\hline $\begin{array}{l}\text { Clinical and } \\
\text { biochemical values }\end{array}$ & $\begin{array}{l}\text { Hemodialysis } \\
\text { patients }\end{array}$ & $\begin{array}{l}\text { Continuous } \\
\text { ambulatory } \\
\text { peritoneal dialysis } \\
\text { patients }\end{array}$ & $\begin{array}{l}\text { Control } \\
\text { patients }\end{array}$ & $p$ \\
\hline $\begin{array}{l}\text { Age (years) } \\
\text { Gender (female/male) } \\
\text { BMI }\left(\mathrm{kg} / \mathrm{m}^{2}\right) \\
\text { Dialysis time (months) } \\
\text { Total cholesterol (mg/dl) } \\
\text { HDL-cholesterol (mg/dl) } \\
\text { LDL-cholesterol (mg/dl) } \\
\text { Triglyceride (mg/dl) } \\
\text { Total protein (g/dl) } \\
\text { Albumin (g/dl) } \\
\text { Dialysate volume (l) } \\
\text { Kt/V } \\
\text { CRP (mg/dl) } \\
\text { Total Hcy }\end{array}$ & $\begin{array}{c}46.6 \pm 14.8 \\
19 / 33 \\
23.8 \pm 3.6 \\
38.3 \pm 15 \\
172 \pm 31 \\
32 \pm 9 \\
102 \pm 22 \\
132 \pm 92 \\
6.9 \pm 1.8 \\
3.4 \pm 0.6 \\
- \\
1.2 \pm 0.2 \\
8 \pm 4.5 \\
32.5 \pm 14.3\end{array}$ & $\begin{array}{l}44.6 \pm 13.5 \\
9 / 17 \\
24 \pm 3.8 \\
17.3 \pm 10 \\
213 \pm 35 \\
35 \pm 8 \\
142 \pm 40 \\
222 \pm 120 \\
7.3 \pm 1.6 \\
3.2 \pm 0.6 \\
9.1 \pm 1 \\
2.2 \pm 0.3 \\
12.8 \pm 9.7 \\
30.4 \pm 18.7\end{array}$ & $\begin{array}{l}45.5 \pm 15.8 \\
8 / 14 \\
24.1 \pm 4 \\
- \\
166 \pm 32 \\
38 \pm 9 \\
102 \pm 29 \\
137 \pm 97 \\
8.4 \pm 2 \\
4.3 \pm 0.6 \\
- \\
- \\
0.3 \pm 0.5 \\
13.2 \pm 5.3\end{array}$ & $\begin{array}{l}\text { Not significant }{ }^{\mathrm{a}, \mathrm{b}, \mathrm{c}} \\
\text { Not significant } \\
\text { Not significant }{ }^{\mathrm{a}, \mathrm{b}, \mathrm{c}} \mathrm{c} \\
<0.001^{\mathrm{a}} \\
<0.05^{\mathrm{c}} \\
\text { Not significant }{ }^{\mathrm{a}, \mathrm{b}, \mathrm{c}} \\
<0.05^{\mathrm{c}} \\
<0.05^{\mathrm{c}} \\
<0.05^{\mathrm{b}} \\
<0.05^{\mathrm{b}, \mathrm{c}} \\
- \\
- \\
<0.05^{\mathrm{a}}{ }^{\mathrm{b}, \mathrm{c}}<0.001^{\mathrm{b}, \mathrm{c}} \\
<0.001^{\mathrm{b}, \mathrm{c}}\end{array}$ \\
\hline
\end{tabular}

Data presented as mean \pm standard deviation, except $*$ number of patients.

a Haemodyalysis versus continuous ambulatory peritoneal dialysis.

bHaemodialysis versus control group.

${ }^{\mathrm{c}}$ Continuous ambulatory peritoneal dialysis versus control group.

CAPD cases (65.4\%) and two of the healthy control group cases (9\%). It was found to be higher than 100 $\mu \mathrm{mol} / 1$ in eight of the HD patients and four of the CAPD patients.

Hcy levels were found to be high in 21 of $25 \mathrm{HD}$ subjects and in 13 of 16 CAPD subjects whose CRP levels were also high. There was a significant positive relation between the serum Hcy levels and serum CRP levels in HD and CAPD subjects $(r=0.384$, $p<0.001)$.

Regarding the 11 patients with coronary artery disease, Hcy levels were found to be high in seven of them and CRP levels were found to be high in five of them and, CRP and Hcy levels together were found to be high in four of them. CRP and Hcy levels were found to be normal in one patient. The Hcy level was above $100 \mu \mathrm{mol} / 1$ in five patients.

\section{Discussion}

The deaths associated with the end-stage renal disease occur as a result of the fatal cardiovascular diseases rather than the direct sequels of uremia, with the exception of poorly developed countries where the deaths associated with this condition also occur as a result of the direct sequels of uremia. Furthermore, the excessive cardiovascular risk has been detected even in the early stages of the renal failure and it persists even after the renal transplantation with a certain high level. ${ }^{1-4}$ The coronary lesion prevalence was shown to be high in the patients with renal disease both by the autopsy reports ${ }^{6}$ and the angiographic studies. ${ }^{7}$ In recent studies it was shown that, as an indicator of chronic inflammation, the proinflammatory cytokines and CRP levels were increased in chronic renal failure, and it is thought that this may be an independent risk factor that may cause progressive atherosclerosis. ${ }^{2-5,8}$ In these studies, it was seen that the serum CRP levels were significantly increased in the subjects who were treated with HD and peritoneal dialysis.

In cases prior to dialysis, the levels of serum CRP, an acute phase protein, were found to be related to the increase in the intima-media surface of the arteria carotis, ${ }^{9}$ other positive and negative acute phase reactants such as albumin, fibrinogen apolipoprotein A-1 and lipoprotein (a), serum amyloid A levels were in correlation with CRP, and some of these proteins may be additional predictor and/or reasonal factors considering the high cardiovascular risk in both HD and peritoneal dialysis patients. ${ }^{2,3,5,9}$

In this study the serum CRP levels were found high in $48.1 \%$ of the HD patients, in $69.2 \%$ of the CAPD patients and in 5\% of the healthy control group patients. No significant relationship could be detected between the serum CRP levels and the age, gender, BMI, dialysis time, total cholesterol, HDLcholesterol, LDL-cholesterol and total protein values in the HD and CAPD subjects. In the HD subjects a negative relationship was detected between the CRP levels and the Kt/V ratios and the albumin, and there was a negative relationship between the serum CRP level and the dialysate volume and the albumin level in the CAPD subjects.

Zimmermann et al. ${ }^{4}$ reported that the increase in the CRP levels was $46 \%$ in the hemodialysis patients. Owen and Lowrie ${ }^{10}$ reported that this increase was $35 \%$. The reason why the ratio of the CRP increase is high in the CAPD group is probably that the inflammation in the CAPD patient can be exaggerated both by the peritoneal irritation and the decrease in the removal of the cytokines because of the decrease 
in the residual renal functions. ${ }^{11}$ This was found to be consistent with the results of our study.

In this study, a negative relationship was detected between the CRP levels and the Kt/V ratios and the albumin levels in the HD subjects, while there was again a negative relationship between the serum CRP level and the dialysate volume and the albumin levels in the CAPD subjects. We did not find an explanatory reason and a comorbid condition about this negative relationship. In the studies a strong relationship was found between the serum CRP levels and the serum albumin level in the HD patients, and also it is suggested that CRP was an important indicator for cardiovascular and total mortality. ${ }^{2,3,5}$

In meta-analyses, the finding of the plasma Hcy level as high was proposed as an independent risk factor for cardiovascular diseases in the general population. ${ }^{8}$ In experimental studies it was shown that hyperhomocysteinemia led to endothelial cell damage, muscle cell proliferation, enhanced lipid oxidation, an increase in thrombocyte aggregation, modulation of the leukocyte-endothelium interaction and interference with clotting factors. ${ }^{2,4}$

Moustapha et $a l .^{12}$ reported the prevalence of hyperhomocysteinemia as $90 \%$ in HD patients and as $67 \%$ in peritoneal dialysis patients. It is shown that $1 \%$ of Hcy that is produced daily by healthy persons was discharged with the peritoneal liquid of those undergoing continuous peritoneal dialysis. In addition, it was shown that there was a relation among hyperhomocysteinemia and cardiovascular diseases, ${ }^{13}$ end-stage renal failure ${ }^{14}$ and vascular access thromboses. ${ }^{15}$ In this study the serum Hcy level was found to be above the normal limits in $73.1 \%$ of HD cases, $65.4 \%$ of CAPD cases and $9 \%$ of the healthy control group.

In this study Hcy levels were found to be high in seven of 11 patients that have coronary artery disease, CRP levels in five patients, and CRP and Hcy levels together in four patients. CRP and Hcy levels were found to be normal in one patient. The levels of Hcy in five patients were determined higher than $100 \mu \mathrm{mol} / 1$.

Finally, in this study it was detected that the serum CRP levels were higher in the HD and CAPD subjects when compared with the control group subjects. Therefore in order to determine the risk rate of Hcy and CRP regarding coronary artery disease, extensive research should be carried out on chronic renal failure patients with coronary artery disease.

\section{References}

1. Foley RN, Parfrey PS, Sarnak MJ. Epidemiology of cardiovascular disease in chronic renal disesase. J Am Soc Nephrol 1998; 9 (Suppl): S16-S23.

2. Eikelboom JW, Hankey GJ. Associations of homocysteine, C-reactive protein and cardiovascular disease in patients with renal disease. Curr Opin Nephrol Hypertens 2001; 10: 377-383.

3. Levey AS, Beto JA, Coronado BE, et al. Controlling the epidemic of cardiovascular disease in chronic renal disease. What do we know? What do we need to learn? Where do we go from here? Am J Kidney Dis 1998; 32: $853-906$.

4. Zimmermann J, Herrlinger S, Pruy A, Metzger T, Warner C. Inflammation enhances cardiovascular risk and mortality in hemodialysis patients. Kidney Int 1999; 55: 648-658.

5. Bayes B, Pastor MC, Bonal J, et al. Homocysteine, C-reactive protein, lipid peroxidation and mortality in haemodialysis patients. Nephrol Dial Transplant 2003; 18: 106-112.

6. Clyne N, Lins LE, Pehrsson SK. Occurrence and significance of heart disease in uremia: an autopsy study. Scand J Urol Nephrol 1986; 20: $307-311$.

7. Rostand SG, Kirk KA, Rutsky EA. Dialysis-associated ischemic heart disease: insights from coronary angiography. Kidney Int 1984; 25: 653659.

8. Danesh J, Lewington S. Plasma homocysteine and coronary heart disease: systematic review of published epidemiological studies. $J$ Cardiovasc Risk 1998; 5: 229-232.

9. Stenvinkel P, Heimburger O, Paultre F, Diczfalusy U, Wang T, Berglund $\mathrm{L}$, Jogestrand T. Strong association between malnutrition, inflammation, and atherosclerosis in chronic renal failure. Kidney Int 1999; 55: 18991911.

10. Owen WF, Lowrie EG. C-reactive protein as an outcome predictor for maintenance hemodialysis patients. Kidney Int 1998; 54: 627-636.

11. Chung SH, Heimburger O, Stenvinkel P, Bergstrom J, Lindholm B. Association between inflammation and changes in residuel renal function and peritoneal transport rate during the first year of dialysis. Nephrol Dial Transplant 2001; 16: 2240-2245.

12. Moustapha A, Gupta A, Robinson K, Arheart K, Jacobsen DW, Schreiber MJ, Dennis VW. Prevalence and determinants of hyperhomocysteinemia and in hemodialysis and peritoneal dialysis. Kidney Int 1999; 55: $1470-$ 1474 .

13. Manns BJ, Burgess ED, Hyndman ME, Parsons HG, Schaefer JP, ScottDouglas NW. Hyperhomocyst(e)inemia and the prevalence of atherosclerotic vascular disease in patients with end-stage renal disease. Am J Kidney Dis 1999; 34: 669-677.

14. Bostom AG, Shemin D, Verhoef $\mathrm{P}$, et al. Elevated fasting total homocysteine levels and cardiovascular disease outcomes in maintenance dialysis patients: a prospective study. Arterioscler Thromb Vasc Biol 1997; 17: 2554-2558.

15. Shemin D, Lapane KL, Bausserman L, Kanaan E, Kahn S, Dworkin L, Bostom AG. Plasma total homocysteine and hemodialysis access thrombosis: a prospective study. J Am Soc Nephrol 1999; 10: 1095-1099.

\section{Received 5 July 2004}

Accepted 9 August 2004 


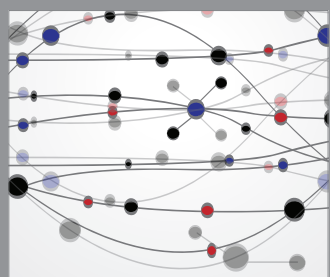

The Scientific World Journal
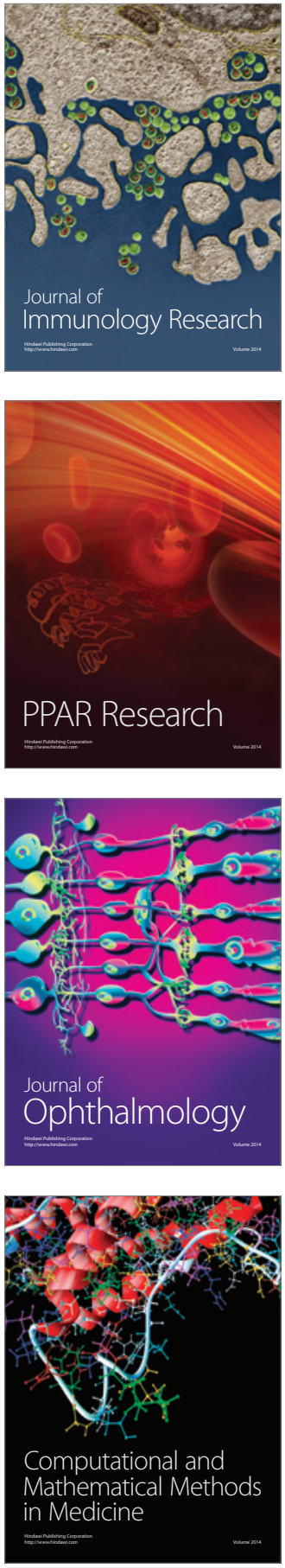

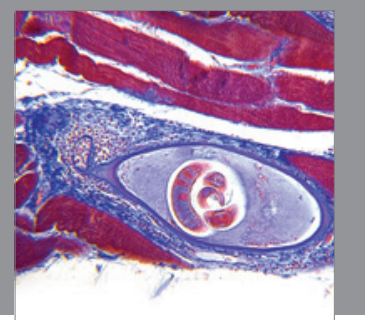

Gastroenterology

Research and Practice
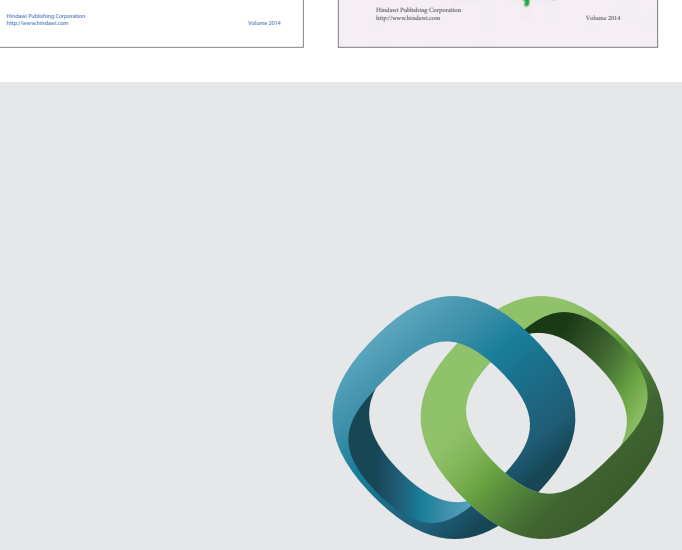

\section{Hindawi}

Submit your manuscripts at

http://www.hindawi.com
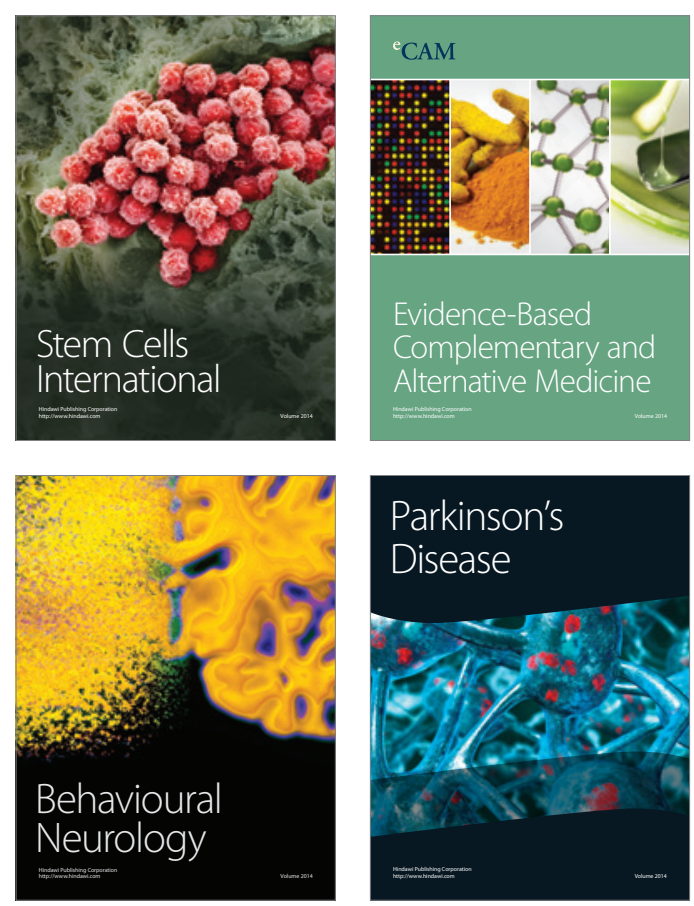

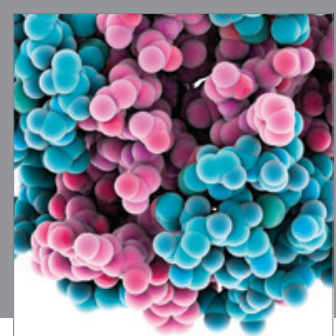

Journal of
Diabetes Research

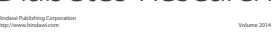

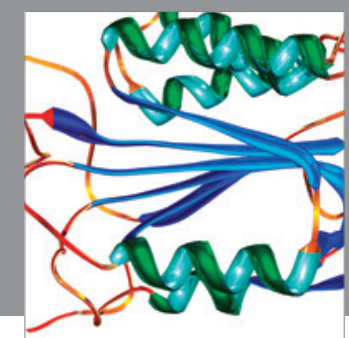

Disease Markers
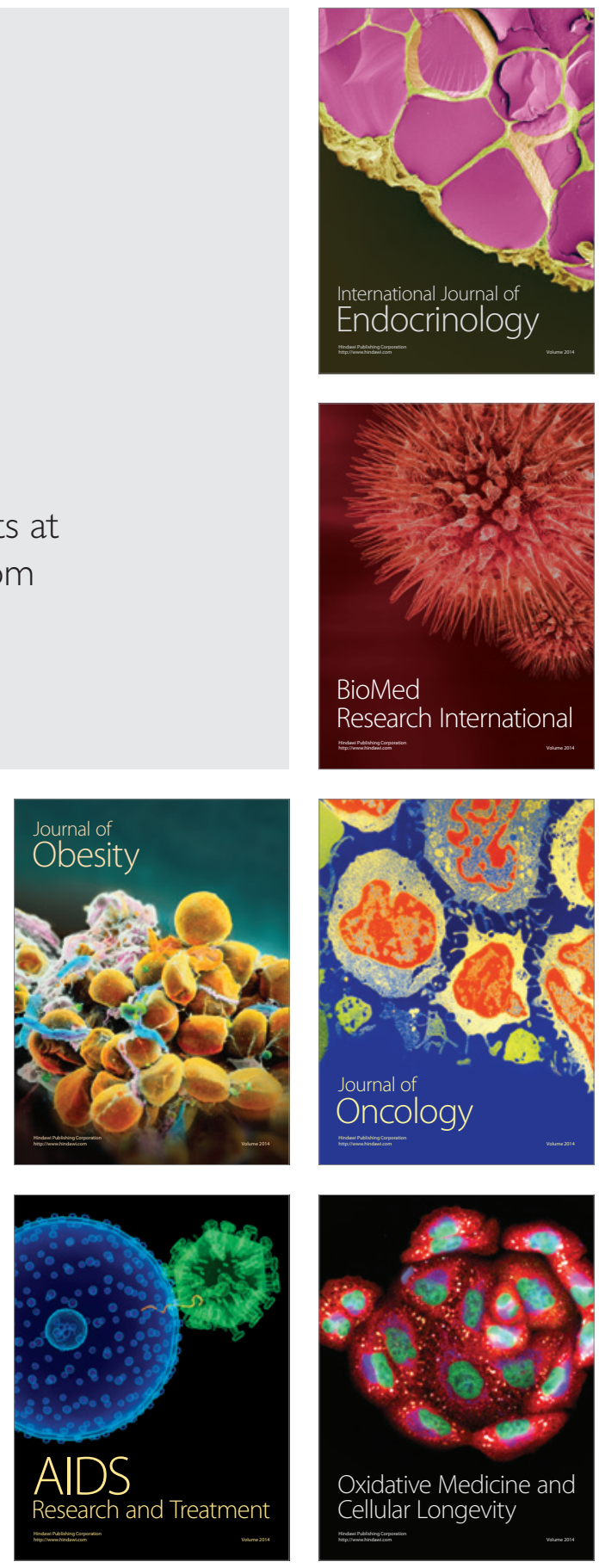